\title{
Graph Algorithms and Applications 4
}

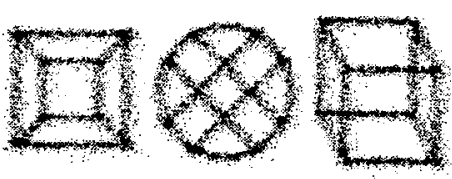


This page is intentionally left blank 


\section{Graph Algorithms and Applications 4}
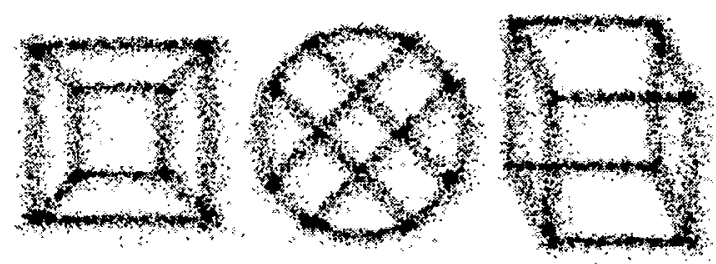

EDITORS

Giuseppe Liotta

University of Perugia, Italy

Roberto Tamassia

Brown University, USA

loannis $\mathbf{G}$ Tollis

University of Crete, ICS-FORTH, Greece and

The University of Texas at Dallas, USA

\section{World Scientific}




\section{Published by}

World Scientific Publishing Co. Pte. Ltd.

5 Toh Tuck Link, Singapore 596224

USA office: 27 Warren Street, Suite 401-402, Hackensack, NJ 07601

UK office: 57 Shelton Street, Covent Garden, London WC2H 9HE

\section{British Library Cataloguing-in-Publication Data}

A catalogue record for this book is available from the British Library.

\section{GRAPH ALGORITHMS AND APPLICATIONS 4}

Copyright 12006 by World Scientific Publishing Co. Pte. Ltd.

All rights reserved. This book, or parts thereof, may not be reproduced in any form or by any means, electronic or mechanical, including photocopying, recording or any information storage and retrieval system now known or to be invented, without written permission from the Publisher.

For photocopying of material in this volume, please pay a copying fee through the Copyright Clearance Center, Inc., 222 Rosewood Drive, Danvers, MA 01923, USA. In this case permission to photocopy is not required from the publisher.

ISBN $981-256-844-1(\mathrm{pbk})$

Printed in Singapore. 


\section{Preface}

This book contains volume 7 of the Journal of Graph Algorithms and Applications (JGAA). Among other papers, the book contains two special issues.

Topics of interest for $J G A A$ include:

Design and analysis of graph algorithms: exact and approximation graph algorithms; centralized and distributed graph algorithms; static and dynamic graph algorithms; internal- and external-memory graph algorithms; sequential and parallel graph algorithms; deterministic and randomized graph algorithms.

Experiences with graph algorithms: animations; experimentations; implementations.

Applications of graph algorithms: computational biology; computational geometry; computer graphics; computer-aided design; computer and interconnection networks; constraint systems; databases; graph drawing; graph embedding and layout; knowledge representation; multimedia; software engineering; telecommunication networks; user interfaces and visualization; VLSI circuits.

$J G A A$ is supported by distinguished advisory and editorial boards, has high scientific standards, and takes advantage of current electronic document technology. The electronic version of JGAA is available on the Web at

$$
\text { http://jgaa.info/ }
$$

We would like to express our gratitude to the members of the advisory board for their encouragement and support of the journal, to the members of the editorial board and guest editors for their invaluable service and to the many anonymous referees for their essential role in the selection process. Finally, we would like to thank all the authors who have submitted papers to JGAA.

Giuseppe Liotta Roberto Tamassia Ioannis G. Tollis 
This page is intentionally left blank

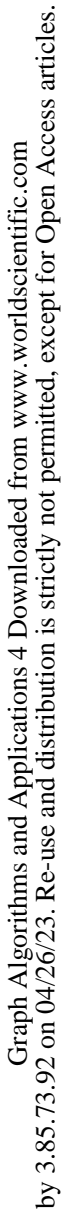




\section{Journal of Graph Algorithms and Applications}

\section{Managing Editor:}

Giuseppe Liotta, University of Perugia

\section{Publication Editor:}

Emilio Di Giacomo, University of Perugia

\section{Editors-in-Chief:}

Roberto Tamassia, Brown University

Ioannis G. Tollis, University of Crete and ICS-FORTH

\section{Advisory Board:}

I. Chlamtac, CREATE-NET

S. Even, Technion

G. N. Frederickson, Purdue University

T. C. $H u$, University of California at San Diego

D. E. Knuth, Stanford University

C. L. Liu, University of Illinois

K. Mehlhorn, Max-Planck-Institut für Informatik

T. Nishizeki, Tohoku University

F. P. Preparata, Brown University

I. H. Sudborough, University of Texas at Dallas

R. E. Tarjan, Princeton University

M. Yannakakis, Columbia University

\section{Editorial Board:}

S. Albers, Universität Freiburg

L. Arge, University of Aarhus

U. Brandes, Universität Konstanz

A. L. Buchsbaum, AT\&T Labs - Research

G. Di Battista, University of Roma Tre

$P$. Eades, University of Sydney

D. Eppstein, University of California at Irvine

M. Fürer, Pennsylvania State University

A. Gibbons, King's College

M. T. Goodrich, University of California at Irvine 
$X$. He, State University of New York at Buffalo

A. Itai, Technion

Y. Kajitani, University of Kitakyushu

M. Kaufmann, Universität Tübingen

S. Khuller, University of Maryland

S. G. Kobourov, University of Arizona

E. W. Mayr, Technischen Universität München

H. Meijer, Queen's University

J. S. B. Mitchell, State University of New York at Stony Brook

B. M. E. Moret, University of New Mexico

P. Mutzel, Universität Dortmund

B. Raghavachari, University of Texas at Dällas

D. Wagner, University of Karlsruhe

T. Warnow, University of Texas at Austin

S. Whitesides, McGill University 


\section{Contents}

Volume 7:1 (2003)

Statistical Analysis of Algorithms: A Case Study of Market-Clearing Mechanisms in the Power Industry. Chris Barrett, Achla Marathe, Madhav Marathe, Doug Cook, Gregory Hicks, Vance Faber, Aravind Srinivasan, Yoram Sussmann and Heidi Thornquist. Communicated by Dorothea Wagner. . . . . . . . . . . . .

Lower Bounds for the Number of Bends in Three-Dimensional Orthogonal Graph Drawings. David R. Wood. Communicated by Dorothea Wagner.

Hamilton Decompositions and (n/2)-Factorizations of Hypercubes. Douglas W. Bass and I. Hal Sudborough. Communicated by Balaji Raghavachari. . . . . . . . . . . . . . . . . 79

Volume 7:2 (2003)

Special Issue on Selected Papers from the Seventh International Workshop on Algorithms and Data Structures, WADS 2001. Guest Editor(s): Giuseppe Liotta and Ioannis G. Tollis.

Guest Editors' Foreword. Giuseppe Liotta and Ioannis G. Tollis. . . . 101 On External-Memory Planar Depth First Search. Lars Arge, Ulrich Meyer, Laura Toma and Norbert Zeh. Communicated by Giuseppe Liotta and Ioannis G. Tollis. . . . . . . . . . . . . . . . . . 105

Small Maximal Independent Sets and Faster Exact Graph Coloring. David Eppstein. Communicated by Giuseppe Liotta and Ioannis G. Tollis.

Deciding Clique-Width for Graphs of Bounded Tree-Width. Wolfgang Espelage, Frank Gurski and Egon Wanke. Communicated by Giuseppe Liotta and Ioannis G. Tollis. . . . . . . . . . . . . . . 141

Visual Ranking of Link Structures. Ulrik Brandes and Sabine Cornelsen. Communicated by Giuseppe Liotta and Ioannis G. Tollis. 181

An Approach for Mixed Upward Planarization. Markus Eiglsperger, Michael Kaufmann and Frank Eppinger. Communicated by Giuseppe

Liotta and Ioannis G. Tollis. . . . . . . . . . . . . . . . . . 203

Upward Embeddings and Orientations of Undirected Planar Graphs.

Walter Didimo and Maurizio Pizzonia . Communicated by Giuseppe Liotta and Ioannis G. Tollis. . . . . . . . . . . . . . . . . . 221

Volume 7:3 (2003)

Crossing Numbers and Cutwidths. Hristo N. Djidjev and Imrich Vrto. Communicated by Giuseppe Liotta. . . . . . . . . . . . . . 245 
A Multilevel Algorithm for Force-Directed Graph-Drawing. Chris Walshaw . Communicated by Michael Kaufmann. . . . . . . . . 253

Finding Shortest Paths With Computational Geometry. Po-Shen Loh. Communicated by Joseph S. B. Mitchell. . . . . . . . . . . . 287

\section{Volume 7:4 (2003)}

Advances in Graph Drawing. Special Issue on Selected Papers from the Ninth International Symposium on Graph Drawing, GD 2001. Guest Editor(s): Petra Mutzel and Michael Jünger.

Guest Editors' Foreword. Petra Mutzel and Michael Jünger. . . . . . . 307

Polar Coordinate Drawing of Planar Graphs with Good Angular Resolution. Christian Duncan and Stephen Kobourov. Communicated by Petra Mutzel and Michael Jünger. . . . . . . . . . . . . . 311

Orthogonal Drawings of Plane Graphs Without Bends. Md. Saidur Rahman, Takao Nishizeki and Mahmuda Naznin. Communicated by Petra Mutzel and Michael Jünger. . . . . . . . . . . . . . . 335

Straight-Line Drawings on Restricted Integer Grids in Two and Three Dimensions. Stefan Felsner, Giuseppe Liotta and Stephen Wismath. Communicated by Petra Mutzel and Michael Jünger. . . . 363

Low-Distortion Embeddings of Trees. Robert Babilon, Jiř Matoušek, Jana Maxová and Pavel Valtr . Communicated by Petra Mutzel and Michael Jünger. . . . . . . . . . . . . . . . . . . . . . 399

On Cotree-Critical and DFS Cotree-Critical Graphs. Hubert de Fraysseix and Patrice Ossona de Mendez. Communicated by Petra Mutzel and Michael Jünger. . . . . . . . . . . . . . . 